\title{
Do direito a ser criança: educação infantil participativa como prática de liberdade
}

\section{The right to be a child: participatory early childhood education as a practice of freedom}

\author{
Ígora Dácio ${ }^{1}$ \\ Joyce Ribeiro $^{2}$
}

\begin{abstract}
Resumo
$\mathrm{O}$ presente trabalho visa analisar como a infância é produzida a partir de uma lógica escolar disciplinar, para torná-la útil, dócil e obediente. No entanto, as crianças conseguem negociar diante desse poder, com a possibilidade de tornarem-se protagonistas dos seus próprios direitos. Acionaremos Ariès (2014), Bujes (2010), Corazza (1998, 2002), Foucault (1971, 2010), e outros/as autores/as cujas contribuições foram fundamentais para 0 debate deste trabalho. O método utilizado foi a etnografia pós-moderna (CLIFFORD, 2016), que permitiu uma escrita sensível sobre os espaços, tempos e sujeitos que contribuíram para a pesquisa. Como resultado, defendemos que a educação enquanto direito, voltada para a cidadania e a democracia, deve necessariamente trabalhar questões como diálogo, escuta sensível, fala ativa, criatividade, expressão, movimento e tantos outros aspectos que permitam a livre manifestação infantil.

Palavras-chave: Direitos; Educação Infantil;
\end{abstract} Liberdade.

\begin{abstract}
The current paper aims to analyze how childhood is produced from a disciplinary school logic to make it useful, docile and obedient. However, children manage to negotiate in the face of this power, with the possibility of becoming protagonists of their own rights. We'll drive Ariès (2014), Bujes (2010), Corazza (1998, 2002), Foucault (1971, 2010), and other authors whose contributions were fundamental to the debate about this paper. The method used was the postmodern ethnography (CLIFFORD, 2016), that allowed a sensitive writing about the spaces, times and subjects that contributed to the research. As a result, we defend that education as a right, focused on citizenship and democracy, it must necessarily work propositions such as dialogue, sensitive listening, active speech, creativity, expression, movement and so many other aspects that allow children's free expression.
\end{abstract}

Key-words: Rights; Childhood Education; Freedom.

\section{Introdução}

Podemos pensar a infância ${ }^{1}$ enquanto o período compreendido entre o nascimento e a adolescência, aquele que carece de proteção e cuidados, a fase de brincar e de se aventurar no mundo da fantasia. Mas afinal a compreensão de que as crianças são detentoras de direitos,

\footnotetext{
${ }^{1}$ Mestra pelo Programa de Pós-Graduação em Cidades, Territórios e Identidades da Universidade Federal do Pará (PPGCITI/UFPA); Especialização em Educação em Direitos Humanos e Diversidade EDHDI/ICJ/UFPA; Graduação em Pedagogia UFPA; Membro do Grupo de Estudos e Pesquisa Gênero e Educação (GEPEGE). Brasil. E-mail: igdacio15@gmail.com | https://orcid.org/0000-0002-8090-8363

${ }^{2}$ Doutora em Educação pela Universidade Federal do Pará (PPGED/ICED/UFPA); Professora de Didática da FAECS/Campus Universitário de Abaetetuba/UFPA; Professora do PPGCITI, na linha de pesquisa Identidades: linguagens, práticas e representações. Líder do Grupo de Estudos e Pesquisa Gênero e Educação (GEPEGE). Brasil. E-mail: joyce@ufpa.br |https://orcid.org/0000-0002-0697-7096
} 
envolve de fato todas as crianças? O que dizer daquelas que não foram alcançadas pela política de proteção integral e foram entregues à própria sorte?

O texto apresentado parte da informação central produzida na pesquisa do mestrado, realizada nos anos de 2017/2018 na Escola Municipal de Educação Infantil em Abaetetuba, no Pará; porém enfatizamos determinados aspectos a partir da perspectiva dos Direitos Humanos. Foram sujeitos da pesquisa 23 crianças do Período I (C) do vespertino, sendo quatorze meninas e nove meninos, na faixa etária de 5 a 6 anos. A escola investigada encontra-se localizada em um bairro composto por um cenário: "problemático de questões sociais, como falta de água, saneamento básico, energia elétrica, habitação e ruas trafegáveis, além da vulnerabilidade da população à violência urbana e ao tráfico de drogas" (GOMES, 2013, p. 163).

Utilizamos como método a etnografia pós-moderna que grosso modo significa a escrita da cultura e possui como pressupostos a ontologia subjetivista que se traduz na observação participante, sem a qual não é possível compreender outra cultura (CLIFFORD, 2016); as conversações, materializadas no diário de campo; a tradução cultural, em que as informações são sistematizadas e analisadas; escritura, que diz respeito ao próprio ato de escrever, porém levando em consideração a subjetividade do/a pesquisador/a.

Buscando analisar como a infância é constituída pela escola, no sentido de adultizá-la, e de que forma essa mesma instituição pode ser um lugar privilegiado para o reconhecimento das crianças enquanto sujeitos de direitos, acionaremos, Ariès (2014), Bujes (2010), Corazza (1998, 2002), Foucault (1971, 2010), dentre outros/as autores/as cujas contribuições foram fundamentais para o debate deste trabalho.

O trabalho está organizado da seguinte forma: iniciaremos abordando a infância em seu caráter legal e histórico; logo após apresentaremos a pesquisa sobre a educação infantil, enfatizando essa etapa da educação básica enquanto alvo do poder disciplinar; em seguida discutiremos o protagonismo infantil; por fim, defenderemos uma Educação Infantil participativa, a fim de garantir que as crianças tenham seus direitos atendidos.

\section{Infância (s)}

Se não vejo na criança uma criança, é porque alguém a violentou antes, e o que vejo é o que sobrou de tudo que lhe foi tirado (Betinho).

A reflexão de Betinho nos leva a pensar sobre a infância embrutecida, aquela cujas crianças, por inúmeros motivos, perderam suas características infantis, seus direitos foram roubados e forçosamente tiveram que amadurecer. Mas quem são essas crianças? Muito além 
de sujeitos abstratos, elas se corporificam cotidianamente nas ruas, na mídia, em espaços responsáveis por torná-las vulneráveis ao inóspito universo adulto.

Para iniciarmos nossa fala, infante é aquele não falante (ARIÈS, 2014), que não tem voz. Discutimos os sujeitos infantis, nesta escrita, não como sujeitos que não falam por incapacidade, por dificuldade em se comunicar. Partimos de uma perspectiva que acredita que estes foram/são propositalmente silenciados, a partir de um projeto que visa privá-los de seus próprios direitos.

Falar em direito das crianças nos remete a alguns marcos na legislação brasileira: A Constituição Federal - CF (1988), também conhecida como constituição cidadã, que foi responsável por reconhecer a criança enquanto sujeito de direitos, tais como à vida, saúde, alimentação e educação; o Estatuto da Criança e do Adolescente - ECA (1990) responsável por garantir uma rede de proteção integral à criança e ao adolescente, responsabilizando a família, comunidade, sociedade e Poder Público pela efetivação de seus direitos. Ao longo da história brasileira, a criança foi tratada de formas bem diversas à concepção atual, como aquela que a considerava como menor em situação irregular ${ }^{2}$, em que elas eram vistas de forma equivocada e até mesmo discriminatória, sem levar em consideração as especificidades de cada fase de desenvolvimento que envolve a infância.

Os sentimentos que envolvem a infância, tais como carinho, cuidado, proteção, são relativamente recentes. Isso porque durante muito tempo as crianças eram consideradas pela sociedade como adultos em miniatura, que deveriam ser precocemente apresentadas ao mundo do trabalho, assim que apresentassem alguma desenvoltura física (ARIÈS, 2014). A educação das crianças não era um direito e nem responsabilidade do Estado e da família, logo, a sua aprendizagem ocorria pela interação com outros adultos.

Ariès (2014) ressalta que durante o período medieval, no século XII, a figura da criança sequer era reconhecida ou representada nas artes, talvez por não haver lugar para a infância nesse período. Foi somente entre os séculos XV e XVI que as crianças passaram a ser retratadas com traços pequenos, não mais como homens e mulheres minúsculos. Percebemos que essa mudança esteve ligada ao novo sentimento da infância "engraçadinha", sendo a criança e suas peculiaridades uma fonte de graça e encantamento.

A ausência das crianças também perdurou por muitos anos na história. Entretanto, com o advento de uma nova história, interessada não apenas nos grandes acontecimentos, mas também pelo espaço privado, como o doméstico e o escolar, a infância começa a conquistar espaço. Até então, a ausência infantil na história é justificada pela ausência dessa fase como objeto discursivo: 
As crianças são as grandes ausentes da história simplesmente porque, no chamado "passado"- da Antiguidade à Idade Média -, não existia este objeto discursivo que hoje chamamos "infância", nem essa figura social e cultural chamada "criança", já que o dispositivo de infantilidade não operava para, especificamente, criar o "infantil", embora já maquinasse como máquina, que vinha operativamente funcionando. (CORAZZA, 2002, p. 81)

Mas afinal, o que é um dispositivo? Acionamos Foucault (2010) a fim de responder essa questão, pois para o autor, dispositivos são estratégias utilizadas para constituir os sujeitos, por meio do poder e do saber. Pode haver um saber que ultrapassa o interesse em conhecer o funcionamento do corpo, que se constitui em uma tecnologia política do corpo que é posta em cena por aparelhos e instituições (FOUCAULT, 2010).

A tecnologia política do corpo se constitui enquanto um mecanismo de dominação, pois visa conhecê-lo com a finalidade de controlá-lo, torná-lo submisso, sujeitado e útil. É uma tecnologia utilizada por diferentes instituições, como prisões, hospitais e escolas, através de inúmeros investimentos voltados para a vigilância, a correção, o controle e a normalização dos corpos. Assim sendo, o dispositivo de infantilidade, termo cunhado por Corazza (1998) trabalha no sentido de exercer domínio sobre o corpo infantil, por meio de investimentos que buscam conhecê-lo para discipliná-lo. Nesse processo, o corpo infantil é território privilegiado, pois é atravessado por técnicas utilizadas para amadurecer biologicamente e ser capaz de se autogovernar.

A administração ao corpo infantil iniciou por volta do século XVII e XVIII, a fim de civilizar a população pobre, por meio do confinamento em instituições, como os asilos, as creches, as escolas maternais e as casas de correção. Nessas instituições, as crianças órfãs eram recolhidas para seu aperfeiçoamento, no caso das meninas, tornarem-se prendadas para o casamento; no dos meninos, ensinar-lhes um ofício para exercer uma profissão.

Vemos nesses investimentos, as mesmas estratégias utilizadas pelo dispositivo de infantilidade, que dizem respeito à produção tanto de ordem física, como ser sadio, limpo e válido, quanto da moral, ser correto, produtivo e ponderado (BUJES, 2010). Isso se tornou possível graças a escolarização, posto que é a partir da permanência na escola que: “[...] se pode melhor trabalhar sobre os corpos a ponto de instrumentalizá-los, investi-los em certa necessidade local-temporal" (OLIVEIRA, 2017).

A escola desponta como palco da produção de discursos, que partem da necessidade de adequação das crianças às normas sociais/culturais. O discurso escolar se incumbe de avaliar, de classificar, quantificar e normalizar os corpos e comportamentos infantis. A produção de discursos não é espontânea ou mesmo intuitiva, ela é proposital, controlada, que possui uma 
materialidade, uma historicidade, com o intuito de domar, cujos procedimentos são capazes de excluir os poderes e os perigos (FOUCAULT, 1971). Enquanto produção o discurso se fixa na história, é pronunciado em um determinado período, época, não é atemporal. Nós mesmos/as somos construídos/as discursivamente, nossas identidades se constroem dentro do discurso e são produzidas em meio às práticas discursivas que surgem em locais históricos e institucionais específicos (HALL, 2000).

Daí a importância de compreender que a infância precisa ser analisada a partir do contexto social, cultural e histórico no qual está inserida. Do mesmo modo, falar sobre a infância requer um sério repensar nesse falar do/sobre o outro de fora, do externo, muitas vezes de forma hierárquica, que tece discursos buscando produzir determinadas verdades acerca do que se espera da infância e de seus sujeitos.

O processo de escolarização é decisivo quando pensamos na domesticação das crianças, sendo um lugar potente na criação de mecanismos para inibi-las, controlá-las de forma eficaz para uma infância correta, limpa e obediente. De outro lado, por uma perspectiva menos fatalista, a escola se apresenta como campo fértil para o reconhecimento das crianças enquanto sujeitos de direitos, protagonistas de suas próprias vidas, capazes de intervir nos problemas sociais, não como meros expectadores, mas provocando-os a atuarem de fato em sua comunidade.

A seguir apresentaremos parte da pesquisa sobre as estratégias utilizadas pela escola a fim de produzir sujeitos infantis disciplinados. A disciplina escolar minuciosamente trabalha no sentido de tolher liberdades, porém descobrimos que também de forma minuciosa as crianças encontram forma de refrear o poder disciplinar.

\section{Disciplina e Infância (s)}

[...] Se eu pudesse correr, sair de casa, molhar-me, enlamear-me, deitar barquinhos no enxurro e fabricar edifícios de areia, com o Sabiá novo, certamente não pensaria nessas coisas. Seria uma criatura viva, alegre (RAMOS, 2010, p. 63) ${ }^{3}$.

Graciliano Ramos, em sua obra "Infância", nos ajuda a refletir sobre a importância da liberdade a uma criança. Brincar, explorar, expressar-se é apenas algumas das infinitas possibilidades criadas por uma criança livre, que ocupa espaços e tempos de forma democrática. No entanto, essa liberdade encontra-se ameaçada, quer por horários inflexíveis, quer pelo cerceamento da circulação infantil por determinados lugares. 
A famosa hora do recreio foi a mais aguardada durante a pesquisa, já que a considerávamos como potente à observação/escritura das relações estabelecidas no seu espaço/tempo. Entretanto, fomos surpreendidas pelo fato de que as crianças lanchavam no interior da sala de aula, sem a liberdade para circular ou brincar lá fora, saindo apenas para ir ao banheiro, o bebedouro ou à cozinha, para devolver a louça utilizada.

Deste modo, questionamos a influência nas crianças do poder disciplinar que, segundo Foucault (2010), garante o controle detalhado das operações do corpo, através de uma constante coerção que esquadrinha tempo, espaço e movimento, visando à fabricação de um corpo dócil, útil e obediente.

A ausência da liberdade infantil para a circulação pelos espaços nos fez compreender como a escola assume um caráter de maquinaria a fim de fabricar um corpo necessário, que diz respeito ao: "indivíduo sujeito a hábitos, regras, ordens, uma autoridade que se exerce continuamente sobre ele e em torno dele, e que ele deve deixar funcionar automaticamente nele" (FOUCAULT, 2010, p. 148). Essa maquinaria inicia desde a demarcação de horários, rigidamente estabelecidos, como forma de educar não somente as mentes, mas também os corpos para estarem adaptados à rotina escolar.

O cotidiano escolar contemporâneo parece converter-se paulatinamente em uma maquinaria messiânica de correção e melhoramento das coisas e das pessoas por meio da ativação de uma infinidade de mecanismos de assujeitamento e de controle produtivo das existências. Uma maquinaria sofisticada que segue operando em estrita consonância ao imperativo máximo da modernidade: educar/disciplinar, agora em suas dimensões mais recônditas. (AQUINO, 2014, p. 108)

Percebemos então, uma forma invisível, porém intencional de controle temporal sobre os corpos infantis, visando "[...] garantir ou buscar a qualidade do tempo empregado" (FERRARI; DINALI, 2012, p. 407). Nesse cenário, a instituição escolar assemelha-se a outras instituições de reclusão, como a prisão, destino daqueles/as que deverão ser corrigidos, higienizados, educados, produtivos. Isso ocorre por meio da avaliação, hierarquização, classificação, reclusão por longas horas, na qual os sujeitos devem adaptar-se aos horários.

Por outro lado, o projeto de disciplinar os corpos infantis, encontrou no recreio, ou melhor, na sua ausência, outra estratégia de conter as crianças, que era justificada da seguinte forma pela professora da turma que acompanhamos: "Olha, elas não saem porque vai virar bagunça, só vão querer saber de correr, não vão lanchar e ainda vão ficar com mau cheiro, aí fica difícil dar aula no segundo horário (Professora Érica)". (Diário de Campo, 18 de Abril de 2017).

Temos aí a construção discursiva acerca do que uma criança deve ser: passiva, porque 
brincar não é uma opção, inodora, afinal o simples odor de seu corpo pode prejudicar o andamento da aula; bem alimentada, pois seu corpo precisa de alimento para sua mente ser alimentada também.

Essa questão nos mostra de que forma o discurso escolar apoia-se no sentido biológico a fim de que as crianças venham a conquistar uma idade adulta ideal, correta e produtiva, que fará parte da população futura: "Percebe-se que a escola atua enquanto dispositivo por constituir sujeitos para atender determinada urgência histórica. Essa edifica as crianças a partir do conceito de infância, buscando adultizá-las" (OLIVEIRA, 2017, p. 68).

O processo de adultização é marcado pela busca incessante da harmonização de três fatores: controle da vida, ou biológico; vigilância acerca da sexualidade; disciplina sobre os outros e autodisciplina, em que a criança reflete sua própria conduta (CORAZZA, 1998). É desse modo que a escola atua, constituindo discursivamente não somente a conduta infantil, mas também seu próprio corpo. Contraditoriamente, o corpo existe nesse contexto, é invisibilizado em sua necessidade de movimentar-se, de socializar com outros corpos por outros espaços, porém a sua necessidade biológica de estar alimentado também é levada em consideração. O corpo infantil no espaço escolar é um mito, acionado quando ela necessita, encoberto quando lhe convém. Não à toa que Louro (2001, p. 60) faz a seguinte provocação:

No 'sagrado' campo da educação não apenas separamos mente e corpo mas, mais do que isso, suspeitamos do corpo. Aparentemente estamos, nas escolas e universidades, lidando exclusivamente com idéias e conceitos que de algum modo fluem de seres incorpóreos.

Apesar desse "esquecimento" dos corpos, eles estão lá, sempre estiveram e estarão. Corpos que sentem necessidades, desejos e prazeres que não podem ser simplesmente postos em segundo plano. Apesar dessa dualidade, há uma complementaridade entre mente e corpo, um abriga o outro e afirmamos seguramente que ambos são fonte do querer, querer este que busca a saciedade por meio da liberdade.

\section{Protagonismo e Infância (s)}

Pensar em educação a partir da LDB nos faz refletir sobre temas caros à mesma legislação, tais como a cidadania e a prática social. De que forma esses valores podem ser trabalhados na Educação Infantil? Como fomentar a criticidade e a participação na primeira etapa da Educação Básica? Teriam as crianças a consciência do seu poder de transformação do cotidiano escolar? 
São questões que nos movem a analisar a educação a partir de um dos princípios bases das Diretrizes Curriculares Nacionais para a Educação Infantil - DCNEI (2010) que é o princípio político: que envolve os direitos de cidadania, assim como o exercício da criticidade e do respeito à ordem democrática. Isso implica em pensar a infância como momento produtivo para o ensaio de práticas que envolvam a consciência, emancipação e liberdade, quer dentro e quer fora do espaço escolar.

A partir disso, podemos compreender o quão potente é trabalhar o princípio político por meio do protagonismo, cuja origem etimológica do termo remete à palavra protagonistés que, em grego, significava o ator principal de uma peça teatral, ou o que ocupava o lugar principal em um acontecimento (FERREIRA, 2004). Nesse sentido, falar em protagonismo infantil nos remete à compreensão das crianças enquanto sujeitos históricos que produzem e são produzidos pela cultura e que, por esta razão, possuem múltiplas potencialidades no que diz respeito ao exercício da cidadania e da liberdade.

As crianças da pesquisa, de forma consciente ou não, compreendiam que eram protagonistas, que a sua liberdade era uma necessidade e para supri-la precisariam criar estratégias de negociação sobre seus tempos e espaços. A seguir iremos expor algumas das imagens selecionadas de uma atividade que propomos acerca desse tema e, logo após faremos sua análise.

Figura 1: Banheiro.

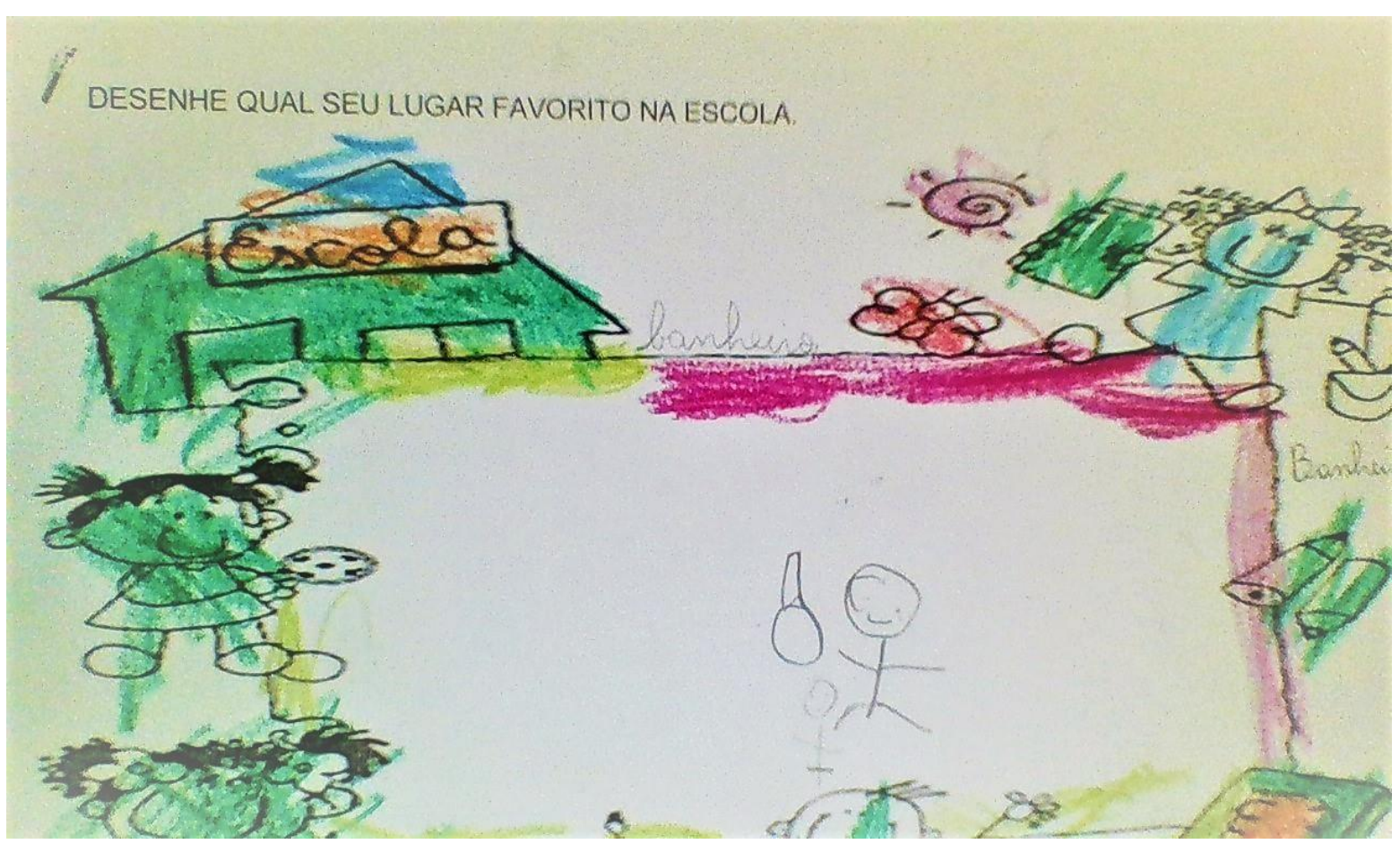

Fonte: Dácio (2017). 
Figura 2: Bebedouro 2.

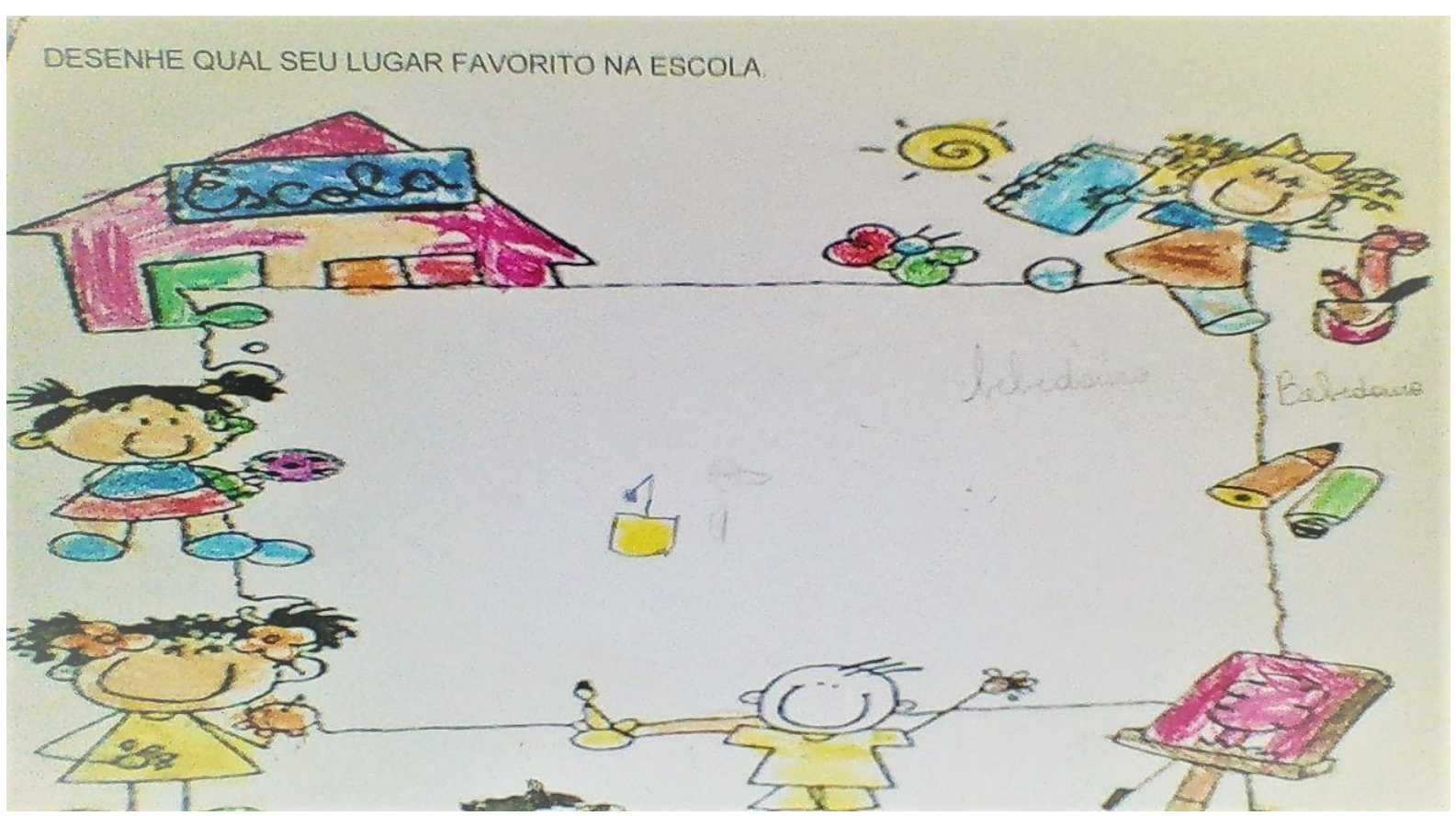

Fonte: Dácio (2017).

As crianças da pesquisa manifestaram seus desejos na busca pela liberdade, a partir da criação de momentos e espaços de resistência para a socialização, onde interagiam com outras crianças, por meio de conversas e por brincadeiras. Essas rotas de fuga eram criadas nos momentos de ir ao banheiro e ao bebedouro, que acabaram se tornando seus lugares preferidos na escola. Por outro lado, observamos também a aceitação de algumas pelo espaço imposto que era a sala de aula e até mesmo os cartazes que a decoravam. Outras, ainda, elegeram a cozinha, o salão e o parquinho como espaços favoritos. Os desenhos foram classificados da seguinte forma: banheiro três (3) crianças; bebedouro três (3); cartazes da sala duas (2); cozinha da escola uma (1); sala de aula uma (1); parquinho uma (1); salão uma (1).

Naquele dia, buscando compreender o porquê de as crianças desenharemaqueles espaços, porém tentando interferir o mínimo possível, decidi questioná-las assim que fossem entregando seus trabalhos.

A primeira que trouxe foi a Isadora e pude observar que ela havia desenhado a cozinha, logo questionei a fim de compreender a razão daquele ser seulugar favorito e ela respondeu: Porque é onde fazem nossa merenda e também a gente pode ir lá comprar pipoca com chopp. Depois começaram a aparecer os desenhos do banheiro e do bebedouro, um deles era de Pedro quedesenhou o banheiro: Porque é quando a gente sai da sala. Em seguida me dirigi para Suane que me respondeu: Eu gosto de ir no bebedouro, porque a professora deixa a gente ir lá. Já Mateus, desenhou a sala, pois: $E$ onde a gente mais fica aqui na escola. Quanto aos cartazes, obtive como resposta 
simplesmente, um: porque sim, do Lucas e da Maria: porque eles enfeitam a sala. (Diário de Campo, 20 de Junho de 2017).

As justificativas das crianças nos ajudaram a compreender como o protagonismo infantil é latente e produtivo no espaço escolar. Esse protagonismo encontra-se intimamente vinculado às identidades dos sujeitos infantis, produzidas em meio às proibições, cerceamentos e quadriculamentos, que buscando discipliná-los, acabava por contribuir com a subversão dos que se negam ao assujeitamento e encontram brechas para exercer a sua liberdade.

A partir das imagens, observamos que algumas crianças encontraram formas de resistir ao poder disciplinar que se faz presente no espaço escolar, que trabalha no sentido de assegurar futuros adultos dóceis e obedientes. O cerceamento, as proibições estimulavam mais ainda a subversão infantil, dos que se negavam a simplesmente se submeter ao domínio escolar. Vemos que a própria disciplina possui seus limites, pois não conseguiu com que todas as crianças fossem resilientes aos seus ditames.

[...] deve-se fazer um breve apontamento: as escolas, no entanto, não são máquinas disciplinares que operam perfeitamente o dispositivo de infantilidade, a ponto de produzir sujeitos corretos que aumentam as forças Estatais. Um dispositivo também produz, nos sujeitos, efeitos de contrapoder - contrário daquilo que se almeja nos indivíduos - e, nessas instituições, conforme observado, em tais sujeitos também são produzidos esses efeitos (OLIVEIRA, 2017, p. 68).

Ainda que a escola possa ser considerada como uma das responsáveis por adultizar a infância, a partir da criação de uma linguagem, um saber e uma técnica para lidar com as crianças, a fim de dirigi-las (CORAZZA, 2002), ela não possui total eficácia. As crianças da pesquisa nos mostraram que apesar de se encontrarem vulneráveis ao intimidador poder disciplinar, elas são inventivas de seus próprios tempos e espaços, desejos e necessidades, reivindicando o principal direito que dá forma ao existir, que é o de ir e vir. Naquele cenário, passamos a compreender os corpos infantis em sua fluidez, em uma provisoriedade que desafia uma complexa maquinaria que trabalha de forma incessante há séculos.

Que contribuições essas crianças podem trazer acerca da liberdade? Suas inquietações nos provocam a inquietar-nos no sentido de questionar os pilares da educação escolar e quem sabe, buscar rotas de fuga, meios para contornar tantas exigências. A forma como os sujeitos infantis são historicamente excluídos do processo de decisões só vem nos mostrar que os pilares da educação escolar, preconizados na Lei de Diretrizes e Bases da Educação Nacional (LDB) são falhos quando reafirmam estarem voltados para a prática social e para o mundo do trabalho.

Assim sendo, propomos a seguir modos de se conectar a essas crianças a fim de garantir o cumprimento de seus direitos. Nessa luta devemos ter em mente que resistir nos provoca a 
criar espaços de luta para as minorias, a diferença, ou o outro se assim preferir, o que implicar em não falar de forma distanciada, com estereótipos que envolvem inocência, incapacidade e tantos simplismos que são acionados ao falar dos sujeitos infantis. Precisamos enxergar as crianças em sua potencialidade como pessoas capazes de fazer história, transformar o contexto no qual estão inseridas.

\section{Cidadania e Infância (s)}

Se a educação escolar, cujo objetivo de acordo com a LDB é a prática social e o mundo do trabalho, pode ser compreendida como uma forma de ascensão social, o que dizer daqueles/as que não tem sequer o acesso aos níveis básicos de escolarização? Como afirmamos, a escola investigada encontra-se localizada em um bairro periférico, em que as crianças encontram-se vulneráveis social/economicamente. De que forma então pensar a Educação Infantil como meio de desenvolvimento integral?

O desenvolvimento que engloba os aspectos físicos, sociais, psicológicos, dentre outros, perpassa por uma Educação Infantil de qualidade, onde as crianças sintam prazer em frequentar a escola, sendo respeitadas e livres em sua singularidade. Por esta razão, a Educação Infantil precisa trabalhar a partir da alegria das crianças em estarem na escola todos os dias, prezando por um fazer pedagógico que venha a estimular as infâncias, pela emoção de estar em seus espaços, que tem a capacidade de proporcionar descobertas no nível social, pessoal, motor e cognitivo, proporcionado pela escola (RODRIGUES, 2016).

No contexto investigado, observamos como essas descobertas ficam comprometidas, quando em detrimento da segurança, da disciplina, são postas em segundo plano. O socializar, o interagir, o brincar são necessidades infantis que merecem estar presente no debate quando o assunto é educação de qualidade, educação no combate às desigualdades sociais.

Para além da desolação, vemos que uma educação de qualidade deve ser ofertada em todos os níveis das redes públicas, porém acreditamos que a educação infantil deve ter muito mais atenção do que têm hoje. É na educação infantil que as crianças criam seus primeiros laços de amizade e sociabilidade, suas noções de respeito perante os outros e recebem seus primeiros aprendizados escolares (RODRIGUES, 2016, p. 31).

Enredadas nas tramas do poder, as crianças entretecem suas relações, quer resistindo, quer aceitando as imposições ditadas pelo espaço escolar e seus sujeitos. Quando escutadas de fato, em seus anseios, as crianças têm a capacidade de tornarem-se protagonistas, não apenas sobreviventes do encarcerador poder disciplinar, mas sujeitos ativos, de participação efetiva na escola. Participar adquire forma através do debate adequado e adaptado ao entendimento delas, 
não uma mera formalidade e sim escuta, no sentido de compreender: quem são? O que querem? O que precisam? Como tornar a escolarização um processo menos doloroso e mais amigável? Acerca desta última questão, acreditamos que não será pela omissão de momentos importantes na rotina escolar, como o recreio.

Fala-se em educação para a cidadania, para a democracia, porém a discussão sobre a relevância da fala e da escuta sensível é omitida. As crianças não são preparadas para essa ação, pelo contrário, precocemente são estimulados/as a se calar, ensinados que para ser alunos/as excelentes precisariam passar despercebidos, falar o mínimo possível, responder quando necessário apenas, obedecer sempre.

[...] A educação para e na participação democrática não só é importante mas também é uma exigência, porque sem ela há o risco de tornar a participação das crianças um processo adultocêntrico, adultonormativo, demagógico e manipulativo. Traz, contudo, vantagens de maior envolvimento e responsabilização das crianças e aumenta o seu sentido crítico e de pertença à sociedade (TOMÁS, 2013, p. 53).

Falar em participação democrática na Educação Infantil implica em trabalhar os aspectos que envolvem a livre manifestação das ideias, o estímulo da criatividade, os movimentos dos corpos, a expressão das emoções que afetam as crianças em seu desenvolvimento. Refletimos então a seguinte questão: se privadas dessas formas de liberdade, se não estão autorizadas a expressar-se, ou se estão apenas em um nível tão limitado que nem conseguem mover as estruturas dos padrões escolares, de que forma falar em educação voltada para a cidadania?

O direito à educação não pode resumir-se ao adentrar o espaço escolar, bem como aos programas suplementares que o poder público tem o dever de garantir, embora reconheçamos a sua necessidade cotidiana. Educação é conquista, resultado de lutas, da mobilização por melhores condições, pelo acesso aos conhecimentos histórica/culturalmente acumulados que trazem a possibilidade da formação de sujeitos críticos, conscientes e participativos.

O direito à educação parte do reconhecimento de que o saber sistemático é mais do que uma importante herança cultural. Como parte da herança cultural, o cidadão torna-se capaz de se apossar de padrões cognitivos e formativos pelos quais tem maiores possibilidades de participar dos destinos de sua sociedade e colaborar na sua transformação. Ter o domínio de conhecimentos sistemáticos é também um patamar sine qua non a fim de poder alargar o campo e o horizonte destes e de novos conhecimentos (CURY, 2007, p. 486).

Quando afirmamos a necessidade de uma educação de qualidade para as crianças, estamos enfatizando uma educação que assegure a participação infantil, como forma de liberdade, como meio de assegurar a cidadania, a liberdade dos corpos e dos pensamentos. 
Defendemos um diálogo em que crianças e adultos tenham voz, em que ambos possam negociar e ocupar os espaços de forma democrática, sem as amarras de uma cultura que vê a criança como incapaz e adulto enquanto ser superior, dotado de capacidades.

Nesse ínterim, precisamos observar os atores-crianças, interesses, suas competências, bem como suas dificuldades, tudo que possa envolver o papel que a criança desempenha na nossa sociedade (TOMÁS, 2013). A partir da compreensão delas, não sobre, mas que parte delas, é possível sim lutarmos por uma educação que venha concretizar a democracia enquanto governo do povo. Povo este composto pela diferença, seja de gênero, sexual, religiosa, econômica e geracional; povo também composto pelos sujeitos infantis e com eles sua criatividade, direitos, corpos, participação e, sobretudo, liberdade.

\section{Considerações finais}

Discutimos ao longo deste trabalho como a escolarização trabalha na produção de uma infância útil, obediente e disciplinada como pela criação de uma rotina com horários inflexíveis e pela exclusão do recreio no cotidiano escolar. Por outro lado, também analisamos o aparato legal que visa justamente garantir a liberdade, a prática social, a cidadania e a criticidade, como a CF, o ECA, a LDB e a DCNEI.

Nesse contexto, observamos a contradição existente entre a legislação que diz respeito à infância e a realidade de uma escola de Educação Infantil, em que a ausência do recreio foi um dos nossos objetos de análise. Observamos então, a escola enquanto uma maquinaria que trabalha incessantemente para produzir corpos submissos, que se resignam diante do poder disciplinar imposto.

No entanto, também ressaltamos que as crianças são criativas e por isso criam formas de se libertar dessa forma de poder. Ora aceitando, ora resistindo, os sujeitos infantis nos mostram como é possível circular entre as tramas do poder e uma dessas formas é inventar estratégias para circular e exercer a liberdade de seus corpos, pequenos em estatura, porém grande em potencialidades.

Demonstramos a partir disso que as crianças podem tornar-se protagonistas, a partir da compreensão de que elas são sujeitos históricos e ativos na produção de suas identidades. Nesse processo, cabe à escola trabalhar com as potencialidades infantis, para que as crianças possam se reconhecer de fato enquanto sujeitos de direitos, capazes de questionar e transformar a realidade na qual estão inseridos. 
Por tudo isso, defendemos que uma educação enquanto direito, voltada para a cidadania e a democracia deve necessariamente trabalhar questões como diálogo, escuta sensível, fala ativa, criatividade, expressão, movimento e tantos outros aspectos que permitam a livre manifestação infantil. É por meio da participação de fato, não como mera formalidade, que a educação desponta como um direito, como forma de liberdade, igualdade e dignidade à grande parte da população que se encontra vulnerável à diferentes tipos de violência e destituída de voz, dentre ela os sujeitos infantis.

\section{Referências bibliográficas}

AQUINO, Julio Groppa. Da autoridade pedagógica à amizade intelectual: uma plataforma para o éthos docente. São Paulo: Cortez, 2014.

ARIÈS. Philippe. História social da criança e da família. Tradução de Dora Flaksman. 2.ed. [Reimpr.]. Rio de Janeiro: LTC, 2014.

BRASIL, Constituição. Constituição da República Federativa do Brasil (1988). Disponível em: http://www.planalto.gov.br/ccivil_03/constituicao/constituicao.htm

BRASIL. Estatuto da Criança e do Adolescente (1990). Disponível em: http://www.planalto.gov.br/ccivil_03/leis/18069.htm

BRASIL. Lei de Diretrizes e Bases da Educação Nacional (1996). Disponível em: http://www.planalto.gov.br/ccivil_03/leis/19394.htm

BRASIL. Diretrizes Curriculares Nacionais para a Educação Infantil (2010). Disponível em: http://portal.mec.gov.br/dmdocuments/diretrizescurriculares_2012.pdf

BUJES, Maria Isabel Edelweiss. Infância e Risco. Educação e Realidade. Porto Alegre, v. 35, n.3, p. 157-174, set./dez., 2010.

CLIFFORD, James. Introdução: Verdades Parciais. A escrita da cultura: poética e política da etnografia. Tradução Maria Claudia Coelho. Rio de Janeiro: Ed. UERJ/Papéis Selvagens Edições, 2016.

CORAZZA, Sandra Mara. História da infantilidade: a - vida - a - morte e mais-valia de uma infância sem fim. 1998. 619f. Tese (Doutorado em Educação) - Universidade Federal do Rio Grande do Sul, Porto Alegre, 1998.

CORAZZA, Sandra Mara. Infância e Educação - Era uma vez - quer que eu conte outra vez? Petrópolis: Vozes, 2002.

CURY, Carlos Roberto Jamil. A gestão democrática na escola e o direito à educação. Revista Brasileira de Política e Administração da Educação - Periódico científico editado pela ANPAE, Brasília, v. 23, n. 3, p. 483-495, set./dez., 2007. 
FERREIRA, A. B. H. Novo Dicionário Aurélio da Língua portuguesa. 3a ed.. Curitiba: Positivo, 2004.

FERRARI, Anderson; DINALI, Wescley. Herança moderna disciplinar e controle dos corpos:quando a escola se parece com uma gaiola. Educ. rev.[online], v. 28, n. 2, p. 393-422, 2012.

FOUCAULT, Michel. Vigiar e punir: nascimento da prisão. Tradução de Raquel Ramalhete. 38. ed. Petrópolis: Vozes, 2010.

FOUCAULT, Michel. A Ordem do Discurso. Tradução de Edmundo Cordeiro e António Bento. L'Ordre du discours, Leçon inaugurale ao Collège de France prononcée le 2 décembre 1970, Éditions Gallimard, Paris, 1971.

GOMES, Jones da Silva. Cidade da arte: uma poética da resistência nas margens de Abaetetuba. Tese de Doutorado, Programa de Pós-Graduação em Ciências Sociais, Universidade Federal do Pará: 2013.

HALL, Stuart. Quem precisa da identidade? In: SILVA, Tomaz T. (Org.). Identidade $e$ diferença: a perspectiva dos estudos culturais. 12a ed. Petrópolis: Editora Vozes, 2000.

LOURO, Guacira Lopes. O Corpo educado: pedagogias da sexualidade. Tradução dos artigos: Tomaz Tadeu da Silva. 2a ed. Belo Horizonte: Autêntica, 2001.

OLIVEIRA, Eduardo Alexandre Santos de. As escolas e o dispositivo de infantilidade. Revista Espaço Acadêmico, Maringá, v. 17, n. 195, p. 58-69, agosto, 2017.

RODRIGUES, Walace. Educação infantil e vulnerabilidade social: infância pobre e sem educação formal. Revista Didática Sistêmica, Rio Grande, v. 18, n. 2, p. 30-42, agosto, 2016.

TOMÁS, Catarina. "Participação não tem Idade" Participação das crianças e cidadania da infância. Revista Contexto \& Educação, Ijuí, v. 22, n. 78, p. 45-68, maio, 2013.

Recebido em 09/06/2021. Aceito em 08/11/2021.

\footnotetext{
${ }^{1}$ Apesar de tratarmos no singular, compreendemos a infância em sua pluralidade, atravessada por diferentes marcadores sociais.

${ }^{2}$ Código de Menores (1979) http://www.planalto.gov.br/ccivil_03/leis/1970-1979/16697.htm

${ }^{3}$ RAMOS, Graciliano. Infância. $45^{\circ}$ ed. revisitada. Rio de Janeiro: Record, 2010.
} 